\title{
Processamento da leitura: decodificação e compreensão
}

\author{
Reading processing: decoding and understanding \\ Procesamiento de lectura: decodificación y comprensión \\ Vera Wannmacher Pereira ${ }^{1} 1$ \\ Fernanda Leopoldina Viana ${ }^{2}{ }^{2}$ \\ José Morais $\oplus^{3}$ \\ 1 Pontifícia Universidade Católica do Rio Grande do Sul, Porto Alegre, RS, Brasil. \\ 2 Universidade do Minho, Braga, Portugal. \\ 3 Universidade Livre de Bruxelas, Bruxelas, Bélgica.
}

\section{A} linguagem é alvo da curiosidade humana desde épocas que nossas memórias alcançam e preservam. Nesse longo percurso, muitos caminhos têm sido trilhados e examinados em suas peculiaridades e em suas convergências. E, assim, os seres humanos mais curiosos vêm se constituindo aos poucos e de diferentes modos nos construtores de uma ciência que a aninha com zelo, seja promovendo o primeiro movimento, seja propondo mudanças decorrentes da necessária dúvida do fazer científico, o que não significa negação da raiz, mas, na verdade, delineamentos produtivos para a sua explicitação e o seu fortalecimento.

Nesse andar, em passos de medidas diversas, que pisam em diferentes pontos, o interesse sobre como essa linguagem se constitui e obtém êxito vai se estabelecendo, em suas manifestações comunicacionais de falar, ouvir, ler e escrever, separadamente e em suas conexões, conforme Maria da Graça Pinto procura ressaltar em seu artigo deste dossiê, ao mencionar as suas propriedades e a sua complementaridade, bem como os usos em momentos oportunos, em suas diferentes contribuições.

$\mathrm{Na}$ linha de tempo de tais estudos, estão inicialmente os estudos normativos caracterizando-se como preditores do uso da linguagem, mais especificamente da língua, considerada como correta e adequada socialmente e desejável em todas as situações. A esses sucedem, no início do século XX, os estudos descritivos e explicativos, ganhando, então, estatuto de ciência linguística e, assim, chegando aos nossos dias. Tal condição favorece o estabelecimento de objetos de estudo, métodos e paradigmas fundantes e abre a possibilidade de definição e redefinição de disciplinas, colaborando, para isso, o ingresso de novos entendimentos e de novas curiosidades.

$\mathrm{O}$ trajeto linguístico amplia o interesse dominante pela língua manifesta para o processo que gera tal manifestação, ocasionando o direcionamento da curiosidade científica para o pensamento humano, o que está presente em Platão, com o mito da caverna, em Humboldt, com os conceitos de ergon e energeia, em Descartes, com a relação entre pensar e existir e em Chomsky, com as concepções de competência e desempenho. Esse interesse pelo pensamento, utilizando hipóteses teóricas, vai gradativamente dando lugar ao interesse pelo cérebro, utilizando hipóteses empíricas, apoiadas por um novo campo de estudos que se estabelece na metade do século XX. Scliar-Cabral (1991), ao expor o surgimento da Psicolinguística, traz importante contribuição para o entendimento de sua relevância para o ingresso nos estudos cognitivos, ultrapassando os assentados na manifestação linguística em si e promovendo interfaces produtivas com a Psicologia, a Fonoaudiologia, a Educação, a Comunicação e as tecnologias.

Essas conexões já são postas como necessárias por Slama-Cazacu (1979) ao apresentar um plano futuro para a Psicolinguística, em que o processo de comunicação, abrangendo o falar, o ouvir, o ler e o escrever, é seu objeto de estudo, a educação é de necessário interesse, incluindo as línguas estrangeiras, e a tecnologia tem lugar relevante. Em relação a esta, há interesse atual no conhecimento do seu impacto no uso pedagógico de trabalho com a leitura.

No prosseguimento histórico, os estudos de Psicolinguística, campo claramente estabelecido, produtivo em suas interações com a Psicologia, a Fonoaudiologia e as Neurociências, incluem os conceitos de processamento da leitura, de memória e de consciência linguística, que estão presentes na temática deste dossiê, de onde a importância de um espaço para alguns comentários estabelecendo algumas relações.

Certamente, o objetivo da leitura de um texto é a sua compreensão. Trata-se de um processo complexo 
cujo aprendizado exige ensino, pois são muitas as condições para o êxito. Uma delas é a decodificação em suas condições orgânicas - o uso da fóvea e dos movimentos sacádicos, conforme o esperado, reconhecendo letras e grafemas, embora as suas diferenças, conforme expõe Scliar-Cabral no seu artigo que integra este material.

Consiste, assim, a decodificação em um processo de reconhecimento e continuado agrupamento das unidades linguísticas, levando ao texto e, assim, chegando à compreensão da leitura. Alessandra Pereira Gomes Machado traz contribuição para o dossiê por meio de uma proposta de diagnóstico de perfil do leitor, considerando as pistas de processos de automaticidade na decodificação que levam à compreensão da leitura. Também Fabiane Basso, Camila Miná, Jerusa Salles e Luciane de Piccolo oferecem contribuição em âmbito próximo, apresentando o instrumento Avaliação de Fluência de Leitura Textual (AFLeT) e um dos estudos de validade do instrumento, cujos resultados indicam que os escores no AFLeT estão significativamente correlacionados com o desempenho em tarefas que medem conceitos teoricamente associados à fluência de leitura.

As definições teóricas já postas assim como os processos e os resultados expostos nesses textos do dossiê confirmam a complementaridade entre decodificação e compreensão, assim como entre microprocessos e macroprocessos e a sua influência na leitura competente, conforme Nakita Marquez e Juliane Silvano indicam em seu artigo de contribuição.

Nessa eficiência buscada, a memória tem importante papel - a de longo prazo, para reunião de conhecimentos prévios, a de curto prazo, para a decisão de realização das ações sucessivas de leitura e a de trabalho, para a garantia da junção dos elementos linguísticos com vistas à chegada na compreensão com o menor tempo possível, de modo a evitar sobrecarga de informação e dificuldade consequente de leitura (MORAIS, 1996). Sobre esse tópico, o texto de Sidnei Woelfer, Lêda Tomitch e Leonilda Procailo oferece uma revisão bibliográfica que oportuniza considerar que há relação entre a maturação da memória de trabalho e o desenvolvimento da metacognição, influenciando a compreensão leitora.

Realizados com êxito o processo de decodificação e o uso das memórias, especialmente da memória de trabalho, cabe ao leitor percorrer o processo de compreensão, tendo à sua disposição o caminho ascendente, das unidades menores para as maiores, em uma leitura linear minuciosa, de composição, em que as partes gradativamente vão formando o todo; o descendente, das unidades maiores para as menores, em um movimento não linear, de decomposição, dirigindo-se da macroestrutura para a microestrutura, com apoio em seus conhecimentos prévios; e o interativo, associando ambos, conforme as situações (SMITH, 2003).

Nessa perspectiva, o processo cognitivo de leitura, dada a sua complexidade, se altera, a partir das variáveis objetivo da leitura, conhecimentos prévios do conteúdo e da língua e características do texto, pois norteadoras de sua definição. O sucesso do desempenho na compreensão da leitura pode estar associado ao uso do processo mais eficiente e das estratégias cognitivas e metacognitivas de leitura mais produtivas para a situação, diferenciando-se na intenção de automonitoramento, portanto na consciência do processo realizado. $\mathrm{O}$ exame dessas estratégias expõe os elementos que internamente as constituem e que estão distribuídos nos planos constitutivos da língua - fônico, morfológico, sintático, léxico-semântico, pragmático e textual (GOMBERT, 1992). Nessa observação, os vocábulos, as estruturas das frases, os significados explícitos e implícitos, os usos inferenciais, todos em seus contextos, têm garantida a sua importância (GIASSON, 2000). Neste dossiê, três artigos tratam de algum modo desses aspectos. Antenor Teixeira de Almeida Júnior, em seu artigo, considera a leitura como uma atividade cognitiva complexa com características de um subsistema que integra um sistema dinâmico maior denominado linguagem, resultante da atuação de diversos fatores que interagem no fluxo do processo de compreensão leitora e de construção de sentido. Adriana Riess e Rosângela Gabriel mostram em seu texto, com base em pesquisa realizada, que as características das palavras e os diferentes tipos de contexto não estão desvinculados do fenômeno da desambiguação, mas que o leitor nem sempre tem ciência de que precisa desambiguar. Denise Almeida, Alina Spinillo e Ilka Lima expõem em seu artigo, investigação realizada sobre a habilidade de crianças em compreender textos argumentativos a partir do estabelecimento de inferências de diferentes tipos, que evidencia, como resultados, ausência de dificuldades das de 8 e 9 anos com as inferências causais e dificuldade das de 8 anos em relação às inferências de previsão.

Desenvolver o ensino da leitura supõe, assim, tomar como objetivo pedagógico o desenvolvimento do processo cognitivo de leitura, o que garante um lugar especial aos planos linguísticos do texto e à consciência linguística, em seus diferentes níveis. Introduzi-lo no ensino, como aspirava Slama-Cazacu (1979), significa promover recortes que examinem e associem os diversos campos linguísticos, do fonológico ao textual, recusando as usuais segmentações dissociadoras (GOMBERT, 1992) assim como os diversos níveis de consciência linguística - da fonológica à textual. Para o alcance desse objetivo, pode ser benéfico o uso de metodologias de ensino e de pesquisa que se comprovem produtivas, como é possível confirmar por meio de quatro artigos do dossiê que 
examinam essas relações, considerando situações de ensino. Dois deles focalizam a consciência fonológica - um de autoria de Jordana Konrad e Aline Lorandi e um de autoria de Fabiane Basso. O primeiro investiga o papel da consciência fonológica como meio facilitador à compreensão leitora de crianças em processo de aquisição da língua escrita, evidenciando que a consciência fonológica contribui tanto para a melhora da leitura e da compreensão quanto para o aumento da velocidade da leitura e da compreensão. O segundo verifica os diferentes níveis de consciência fonológica de crianças francesas no início e no final do ano escolar, demonstrando, conforme os dados coletados, melhores resultados do grupo B (em relação ao A) no início do ano escolar, com ausência de diferenças significativas entre os grupos A e B no final do ano, a indicar a possibilidade de o contexto didático e pedagógico ter desempenhado um papel importante. Dois outros voltam-se para o uso de estratégias de leitura. O primeiro, de Danielle Baretta, Thaís dos Santos e Caroline Borges, examina a contribuição de materiais de leitura com foco na consciência linguística e no uso de estratégias de leitura (predição, scanning e leitura detalhada) para alunos de 9으 ano do Ensino Fundamental, tendo como resultado a existência de diferenças significativas entre o pré e o pós-teste no uso e na consciência linguística no uso das estratégias de leitura, comprovando os benefícios do material de leitura para esses alunos. O segundo, de Fernanda Franco Tiraboschi e Francisco José Quaresma de Figueiredo, investigando os eventuais efeitos da instrução de estratégias cognitivas, metacognitivas e de navegação para a realização de tarefas automonitoradas de leitura hipertextual em língua inglesa, demonstra o aprendizado, pelos participantes, das estratégias trabalhadas e o alcance de uma compreensão melhor do hipertexto a partir do uso desses recursos.

Essa perspectiva de desenvolvimento do processo cognitivo de leitura supõe também reconhecer a sua relação com a escrita, pois ler e escrever são processos que, em suas diferenças, estão profundamente associados. Como indica Smith (2003), o leitor é um escritor, uma vez que lê buscando as pistas deixadas por quem escreveu o texto. Na mesma condição, ao escrever, o escritor tem como referência o leitor, assim como ao refazer a sua própria escrita volta-se novamente para quem fará a leitura do seu texto (ele próprio e um outro). Luís Barbeiro, em sua contribuição neste dossiê, relata, em decorrência de estudo com escrita colaborativa, um alargamento das possibilidades consideradas, ao longo do processo de construção do texto, dos anos iniciais para os anos mais avançados. Dina Alves e Ana Rita Carvoeiro apresentam, em seu artigo, instrumento que tem por base uma visão holística do processo de escrita. Dulce Helena Melão expõe, em seu texto, estudo realizado sobre as práticas de leitura e de escrita de estudantes de Comunicação Social, que indica que a maioria deles prefere ler em suporte impresso, têm práticas de escrita diversificadas, sobressaindo os textos pessoais e as notícias e valorizando o contributo da escrita criativa.

$\mathrm{Na}$ continuidade dessa perspectiva, considerando o alcance de objetivo pedagógico, estão presentes também nos estudos as variáveis vinculadas ao professor - os seus conhecimentos teóricos e as suas condições de transposição didática, pois nesse cruzamento está o espaço que pode favorecer o sucesso do leitor. Em relação ao domínio teórico, Terezinha Oliveira, Magaly Minatel e Sandra Guimarães, em sua contribuição neste dossiê, indicam evidências em suas pesquisas de que as manifestações dos professores revelam pouca clareza quanto aos conteúdos e conceitos referentes à dimensão cognitiva da leitura, limitando a utilização de efetivas propostas de ensino da compreensão leitora. Em relação ao uso de procedimentos didáticos produtivos, Helena Corso, Évelin Assis, Débora Nunes e Jerusa de Salles, enfatizam, em seu artigo, a clara implicação educacional da instrução como chave para o desenvolvimento da compreensão leitora, sendo efetiva na medida em que for compatível com as habilidades linguísticas e sociocognitivas aportadas pelo aprendiz.

Fechando as análises, cabe realizar ainda algumas reflexões em relação a definições importantes do dossiê. O recorte aqui desenvolvido, como é possível constatar, é construído na temática estabelecida e nas produções colaborativas encaminhadas por pesquisadores vinculados a diferentes instituições - de âmbito local, nacional e internacional, valorizando a heterogeneidade teórica, metodológica e pedagógica, própria da construção do conhecimento. A teórica está na escolha do modelo de suporte das definições de fundo, a metodológica na eleição do delineamento dos caminhos para realização dos estudos e a pedagógica no processo cognitivo para construção da decodificação e da compreensão em suas relações com a consciência e a memória.

Nessa dimensão, ganha relevância o ponto de vista de que o processo cognitivo se realiza em rede, exigindo do usuário o manejo de processos ascendentes $\mathrm{e}$ descendentes e de estratégias cognitivas e metacognitivas. Do mesmo modo, recebe valor o entendimento de que a consciência (GOMBERT, 1992) pode focalizar determinado segmento linguístico, considerando sempre o contexto dos demais segmentos. Tais relevâncias contribuem para a aproximação de áreas e para estudos da construção cognitiva e cultural da leitura, o que confere à Psicolinguística e suas interfaces produtivas, como já referido ao longo deste Editorial, possibilidades importantes de contribuição para o desenvolvimento desses conhecimentos e ao presente dossiê, por meio 
dos textos de seus autores, um registro significativo de pesquisas nessa direção.

Ao longo do texto, estão alguns fundamentos desse recorte, baseados em obras que historicamente vêm configurando a área teórica do dossiê. Esses fundamentos são comentados com base no desenvolvimento produtivo dos artigos dos colaboradores, por sua atualidade e pertinência, sendo assim tramados. A uns e outros, cujos trabalhos contribuem para o aprofundamento e a ampliação dos estudos psicolinguísticos em suas interfaces, registre-se aqui, com honra devida, reconhecimento e agradecimento, com a expectativa de que o presente dossiê corresponda às expectativas dos colaboradores e de suas instituições, assim como dos leitores interessados que se debruçarem sobre os artigos disponibilizados.

\section{Referências}

DEHAENE, Stanislas. Os neurônios da leitura. Como a ciência explica a nossa capacidade de ler. Porto Alegre: Artes Médicas, 2012.
GIASSON, Jocelyne. A compreensão na leitura. Lisboa: ASA, 2000.

GOMBERT, Jean. Émile. Metalinguistic development. Chicago: The University of Chicago Press, 1992.

MORAIS, José. A arte de ler. Psicologia cognitiva da leitura. São Paulo: Editora da Universidade Estadual Paulista, 1996.

SCLIAR-CABRAL, Leonor. Introdução à Psicolinguística. São Paulo: Ática, 1991.

SLAMA-CAZACU, Tatiana. Psicolinguística aplicada ao ensino de línguas. São Paulo: Pioneira. 1979.

SMITH, Frank. Compreendendo a leitura. Uma análise psicolinguística da leitura e do aprender a ler. Porto Alegre: Artes Médicas, 2003.

Recebido em: 22/7/2019.

Aprovado em: 22/7/2019

Publicado em: 5/11/2019.

\section{Organizadores:}

Vera Wannmacher Pereira

Doutora em Letras - Linguística Aplicada pela Pontifícia Universidade Católica do Rio Grande do Sul (PUCRS). Professora Titular Permanente da Escola de Humanidades/Letras.

Orcid: https://orcid.org/0000-0001-8829-1313

E-mail: vpereira@pucrs.br

Endereço: Av. Ipiranga, 6681 - Partenon

90619-900, Porto Alegre, RS, Brasil

FERNANDA LEOPOLDINA Viana

Doutora em Psicologia da Educação pela Universidade do Minho (UMinho). Professora Associada no Instituto de Educação da Universidade do Minho.

Orcid: http://orcid.org/0000-0002-5101-6454

E-mail: fviana@ieuminho.pt

Endereço: Rua da Universidade

4710-057, Braga, Portugal

José Morais

Professor Emérito da Universidade Livre de Bruxelas (ULB).

Exerce sua atividade científica como professor convidado na

Unidade de Pesquisa em Neurociência Cognitiva (UNESCOG) do

Centro de Pesquisa em Cognição e Neurociências da ULB.

Orcid: https://orcid.org/0000-0002-8079-5098

E-mail: jose.junca.de.morais@ulb.ac.be

Endereço: Avenue Franklin Roosevelt 50

1050, Bruxelles, Bélgica 